University of Massachusetts Amherst

ScholarWorks@UMass Amherst

Chemistry Department Faculty Publication Series

Chemistry

2001

\title{
Anticarcinogenic organoselenium compounds - Chromatographic, atomic and molecular mass spectral speciation
}

PC Uden

R Hafezi

M Kotrebai

P Nolibos

J Tyson

See next page for additional authors

Follow this and additional works at: https://scholarworks.umass.edu/chem_faculty_pubs

\section{Recommended Citation}

Uden, PC; Hafezi, R; Kotrebai, M; Nolibos, P; Tyson, J; and Block, E, "Anticarcinogenic organoselenium compounds Chromatographic, atomic and molecular mass spectral speciation" (2001). PHOSPHORUS SULFUR AND SILICON AND THE RELATED ELEMENTS. 1035.

Retrieved from https://scholarworks.umass.edu/chem_faculty_pubs/1035 
Authors

PC Uden, R Hafezi, M Kotrebai, P Nolibos, J Tyson, and E Block 


\title{
Anticarcinogenic Organoselenium Compounds - Chromatographic, Atomic and Molecular Mass Spectral Speciation
}

\author{
PETER C. UDEN ${ }^{\mathrm{a}}$, RAMEH HAFEZI $^{\mathrm{a}}$, MIHALY KOTREBAI ${ }^{\mathrm{a}}$, \\ PAULA NOLIBOS ${ }^{\mathrm{a}}$, JULIAN TYSON ${ }^{\mathrm{a}}$ and ERIC BLOCK ${ }^{\mathrm{b}}$ \\ ${ }^{a}$ Department of Chemistry, University of Massachusetts, Amherst, \\ MA 01003-4510, USA and ${ }^{\mathrm{b}}$ Department of Chemistry, SUNY-Albany, Albany, \\ NY 12222, USA
}

There is substantial evidence of the complexity of selenium speciation in living organisms and of the importance of the selective determination of the particular species of this element in order to understand its metabolism and biological significance in clinical chemistry, biology, toxicology, and nutrition. The state-of-the-art of analytical techniques available for this purpose is critically evaluated with particular emphasis on the element-selective detection and identification of the detected selenium compounds. Whereas there are a number of techniques available, which can detect various selenium species in living organisms selectively, few techniques exist that are able to identify and to characterize the species detected.

Keywords: Selenized natural products; garlic; yeast; chemical speciation of selenium; selenium cancer prevention 


\section{INTRODUCTION}

Selenium has an established nutritional role and substantive cancer chemopreventive properties but the speciation of inorganic and organoselenium compounds, needed to define their biological roles, presents great anslytical challenges. Selenium toxicity also mandates high accuracy and precision in analytical measurement. Selenium is essential for life but toxic at levels little above those required for health Consumption of food containing less than $0.1 \mathrm{mg} \mathrm{kg}^{-1}$ will result in its deficiency but levels above $1 \mathrm{mg} \mathrm{kg}^{-1}$ induce toxicity ${ }^{[1]}$. The essentiality of selenium derives in part from its role in forming the active selenol group (-SeH), center, of ghtathione peroxidase, thioredoxin reductase and of other selenoenzymes ${ }^{[2,3]}$. Cancer chemoprevention is associated with inorganic selenium salts and some selenoarninoacids and synthetic organoselenium compounds. Monomethylated forms of selenium such as methylselenol $\left(\mathrm{CH}_{3} \mathrm{SeH}\right)$ are important chemopreventive selenium metabolites $^{[4]}$.

In biological systems, selenium is not coordinated, but forms covalent carbon-selenium (C-Se) bonds, in contrast to metal-protein complexes. Selenium species in the living body can be classified as enzyme products and gene products. The former are present as products of enzymatic reactions such as reduction, methylation, and of reactions 
leading to selenoamino acid synthesis. Selenium is incorporated into the gene products, according to the UGA codon, which encodes the selenocysteinyl residue. Selenoproteins therefore contain selenium in the form of selenocysteinyl residues; proteins that contain this element in the form of selenomethionyl residues are not formally classified as selenoproteins.

The wide range of selenium species in natural systems presents a challenge to the anabytical chemist. Arabytical techniques for the determination of selenium species, including selenoproteins were reviewed ${ }^{[5-9]}$. Many methods have only been applied to the commercially available standands rather than to address a particular biochemical problem.

Ionic, zwitterionic and neutral selenium species are all present in or bound to both enriched and natural matrixes. Selenium chemistry and biochemistry parallels in part sulfur chemistry and this presents analytical challenges since it is presem in narure at levels more than a thousandfold lower than sulfur. The bioavailability of anionic, cationic and neutral selenium compounds, and selenoamino acids such as selenocystine, selenomethionine, Se-methylselenocysteine etc. is of much clinical interest, but low level determinations are very difficult.

Table 1 shows a list of selenium species which has attracted recent nutritional, clinical and bioanalytical attention. 
TABLE 1. Inorganic and organoselenium analytical target compounds

\begin{tabular}{|c|c|}
\hline $\begin{array}{l}\text { Selenious Acid, selenite } \\
\text { Selenic Acid, selenate }\end{array}$ & $\begin{array}{l}\mathrm{SeO}_{3}^{2-} \\
\mathrm{SeO}_{4}^{2-}\end{array}$ \\
\hline Selenayanate & SeCN \\
\hline Mathylseleninic acid anion & Maseroyo \\
\hline Mathylseleneric acid anion & $\operatorname{mas} 0$ \\
\hline Dimethylselenide & $\mathrm{Me} 2 \mathrm{Se}$ \\
\hline Dimethyldiselenide & $\mathrm{Me}_{2} \mathrm{Se}_{2}$ \\
\hline Mathylselenol & MaSeH \\
\hline Trimethylselenonium cation & $\mathrm{MezSe}^{+}$ \\
\hline Selenogsteine & $\mathrm{H}_{3} \mathrm{~N}^{+}-\mathrm{CH}_{1} \mathrm{COO}-\mathrm{CH}_{2} \mathrm{SeH}$ \\
\hline Selenogystine & $\mathrm{H}_{3} \mathrm{~N}^{+}-\mathrm{CH}_{1} \mathrm{COO}^{-} \mathrm{CH}_{2} \mathrm{SOSO}_{-} \mathrm{CH}_{2} \mathrm{CH}_{1} \mathrm{COO}^{-} \mathrm{HWH}_{3}{ }^{+}$ \\
\hline Selenomethionine & $\mathrm{H}_{3} \mathrm{~N}^{+}-\mathrm{CH}_{1} \mathrm{COO}^{-} \mathrm{CH}_{2} \mathrm{CO}_{2}$ Some \\
\hline Se-methylselengystaine & $\mathrm{H}_{3} \mathrm{~N}^{+}-\mathrm{CH} \mathrm{COO}^{-} \mathrm{CH}_{2}$ SOM \\
\hline$\gamma$-Glutamyl-Se-methylselerogsteine & $\mathrm{H}_{3} \mathrm{~N}^{+}-\mathrm{CH}_{2} \mathrm{CH}_{2} \mathrm{CONH}_{2} \mathrm{CHCOO}_{2}^{-} \mathrm{CH}_{2}$ Soms \\
\hline Selenocysenthionine & $\mathrm{H}_{3} \mathrm{~N}^{+}-\mathrm{CH}_{4} \mathrm{COO}_{-}^{-} \mathrm{CH}_{2} \mathrm{CH}_{2} \mathrm{SOCH}_{2} \mathrm{CH}_{4} \mathrm{COO}_{-\mathrm{NH}_{3}}^{+}$ \\
\hline Selenotumagsteine & $\mathrm{H}_{3} \mathrm{~N}^{+}-\mathrm{CH}_{4} \mathrm{COO}_{-}^{-} \mathrm{CH}_{2} \mathrm{CH}_{2} \mathrm{SeH}$ \\
\hline Se-adenosylseloohamaysteine & 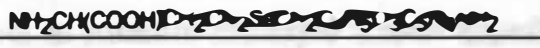 \\
\hline
\end{tabular}

A recent human intervention trial showed that daily dietary supplementation with selenized brewers' yeast led to a decrease in lung, colon, and prostate cancer morbidity and mortality by nearly $50 \%{ }^{[10]}$. Past research has also demonstrated that selenized garlic is very effective in marmmary cancer chemoprevention in the rat model ${ }^{[1-13]}$. Chemical species present were incompletely characterized in these studies however.

Species-selective determination of selenium compounds in biological materials has been critically reviewed recently ${ }^{[14]}$. A major analytical advantage in this field is that the presence of the selenium 
atom in analytes has enabled the application of element specific atomic spectral detection for chromatographic eluent monitoring, allowing quantitative speciation to be developed. In the present paper the fluoroacid ion pair high performance liquid chromatography (HPLC) with inductively coupled plasma mass spectral (ICP-MS) detection, electrospray ion trap HPLC-MS and direct or derivatization gas chromatography with atomic emission detection (AED) are discussed as aids for definitive speciation analysis and elucidation of reaction pathways.

\section{ANALYTICAL SELENIUM SPECIATION}

\section{Liquid Chromatographic Methods}

The separation, qualitative identification and quamitative determination of the wide range of inorganic selenium and organoselenium present or potentially present in complex materials presents a great challenge to the anabytical chemist and requires the application of a complementary range of state-of-the art techniques.

High Performance Liquid Chromatography (HPLC) provides the core methodology, since many of the target chemical species are not amenable to gas phase separations. In essence the noed is to develop and apply a complementary suite of separation methods which when applied together will give the greatest confidence of reliable information. 
The Reverse Phase Ion Pair HPLC mode has been the most successful. The stationary phase is a non-polar bonded silica matrix and the mobile phase is polar incorporating a fluorinated acid ion-paining agent to establish a pH of ca. 2. Selenium anions (selenite, selenate etc.) are protonated completely at this $\mathrm{pH}$ to give neutral species, which are eluted very early in the chromatogram. Cationic (positive) species such as trimethylselenonium are paired with the fluorinated acid anion ( e.g. triffuoroacetate ) to give 'neutral' ion pairs and are retained somewhat more and elute later. Selenoamino acids are protonated and also "ion paired' with the fluoroacid anions and elute at different times depending upon their degree of retention on the stationary phase. Different fluorinated acids provide different degrees of separation in different regions of the chromatogram. Larger molecules such as peptides and proteins are not eluted and separated by this procedure although intermediate species such as Se-adenosylselenohomocysteine and gamma-glutamyl-Se-methylseleno cysteine can be eluted in a reasonable time frame.

In Anion Exchange chromatography, separation is by a combination of size and charge of negative (anion) forms of the analyte species. The column incorporates a positive surface, usually with a quatemary ammonium functionality and the $\mathrm{pH}$ of the column is basic, typically 8-9. In this system, selenoamino acids are deprotonated and elute first as anions, separation depending on the relative affinities of these anions with the positive surface. Species such as selenite and selenate elute later. This elution order is opposite to that of reverse phase ion pair separation. Cation Exchange chromatography offers more 
parallel separation to reverse phase methods. The column incorporates a negative ( anion ) surface and positively charged species are selectively separated at acid $\mathrm{pH}$ conditions, typically 3-4. The elution order has anions such as selenite eluting with virtually no retention, amino acids eluting later depending upon their $\mathrm{pKa}$ values and column affinities. In general ion exchange methods do not offer as high separation efficiencies as reverse phase methods.

Chiral HPLC is a relatively new separation mode, which is applicable primarily to selenoaminoacids and species such as Seadenosylselenohomocysteine and gamma-glutanyl-Se-methylseleno cysteine, which have chiral (asyrumetric) centers and thus optically active forms. The principle of separation involves selective retention on a stationary phase such as a 'crown ether' which has differing affinities for different optically active forms of the same compound. Elution order is not $\mathrm{pH}$ controlled but depends additionally on overall reverse phase partition of the species into the crown ether phase. Output from this system has features of the reverse phase ion pair and ion exchange modes and gives a separation of target analytes with the added feature of chiral separations where such enantiomeric species are present.

A viable instrumental method must be specific for a particular selenium species or the species must be separated in time or space before presenting to a selenium-specific detector. The first group of techniques includes radioimmunological assays (RIA) for selenoproteins that have very low detection limits but require the proteins to be isolated in adequate amounts for antibody production. Flatbed electrophoresis offers a much better resolution than HPLC for such separation, the fact 
that Se is bound via a covalent bond allowing the use of SDS PAGE without the risk of Se losses. Complementary separation mechanisms are necessary. For example, the isolation of the protein fraction by anionexchange chromatography was recommended prior to $\mathrm{PAGE}^{[15]}$. Autoradiography is the principal technique used for the detection of selenoproteins in gel strips; alternatively, they can be Western blotted onto nitrocellulose membranes in which $\mathrm{Se}$ is determined by instrumental techniques such as Neutron Activation Analysis or and X-Ray Fluorescence.

The second approach, using so-called hyphensted techniques, involves coupling of an electrophoretic or chromatographic separation technique with a Se-specific technique such as atomic or mass spectrometry. Such coupling can be accomplished off-line, e.g. SDS-PAGE with instrumental neutron activation analysis (INAA), or on-line, e.g. HPLC - ICP-MS. The principle of coupled techniques has been widely discussed elsewhere ${ }^{[16,17]}$. Selenium species (Se (IV), Se (VI), selenomethionine and selenocysteine) were often used as examples in experimental developments.

\section{Gas Chromatographic Methods}

Capillary gas chromatography provides sensitive, high-resolution analysis, directly for analytes of sufficient volatility, or following chemical derivatization to convert nonvolatile species to volatile ones. When coupled with atomic emission detection (AED), selenium in target 
molecules is directly monitored by spectroscopic detection of atomic emission radiation at a wavelength characteristic of the element, providing both qualitative elemental speciation and quantitation. ${ }^{[18,19]}$ We have used GC-AED to detect and determine many volatile organoselenium compounds present in or produced by plants. Headspace-GC-AED has been used to detect many selenium compounds in Alliums, such as garlic, elephant garlic, onion and broccoli: ${ }^{[20]}$. A common structure is $R-S_{\mathbf{x}}\left(\mathrm{Se}_{\mathbf{y}}\right)-\mathrm{R}^{\prime}$, where the $\mathrm{R}$ and $\mathrm{R}^{\prime}$ are methyl or allyl groups. Natural abundance organoseleniun compounds in human breath after ingestion of garlic were identified using Tenax trap/cryogenic-GC-AED ${ }^{[21]}$. The presence of selenium species in kerogen sedimems by derivatization pyrolysis-GC-AED ${ }^{122 !}$, tetrabutyl ammonium hydroxide reagent being used for on-line butylation of polar hydroxyl and carboxyl functionalities. Preliminary data from GC-AED of extracts from cretaceous shales suggests the presence of arylselenophenes analagous to condensed thiophenes. Our approach is to use GC-AED in combination with various sample introduction methods to identify and determine volatile selenium species in various matrixes.

Selenoaminoacids have been derivatized for GC with isopropylchloroformate and bis (p-methoxyphenyl) selenoxide ${ }^{[23]}$, with pyridime and ethyl chloroformate $\mathrm{e}^{[2 /]}$ or silylated with bis (trimethylsilyl)acetamide $^{[23]}$. Selenomethionine forms volatile methylselenocyanide with $\mathrm{CNBr}^{[26,27]}$ Selenocysteine, Se-methyl selenocysteine, and selenomethionine in normal and selenium-enriched plants were determined using GC-AED of ethylated derivatives after ethyl chloroformate reaction ${ }^{[24]}$, selenoxides or selenones as yet 
uncharacterized, may also be present in plants and determinable by GCAED. The potential of GC-AED to confirm elemental composition relates well to a GC-MS study by Chasteen ${ }^{\text {[28] }}$ who showed the error of an attribution of a peak to dimethylselenone (methyl methylselenite) $\left[\left(\mathrm{CH}_{3}\right)_{2} \mathrm{SeO}_{2}\right]$ which was in fact dimethyl selenyl sulfide $\left[\mathrm{CH}_{3} \mathrm{SeS} \mathrm{CH}_{3}\right]$.

\section{Atomic and Molecular Mass Spectrometry}

Figure 1 shows natural isotopic abumdarce for selenium, potential ICP-MS ion interferences, and single and double selenium ion profiles. In HPLC-ICP-MS, an important experimental factor for the lowresolution quadrupole mass spectrometers, which are most often used, is interference from common ions deriving from plasma gas (argon) or other elements. Thus in most studies, ${ }^{82} \mathrm{Se}$ has been preferred since the interferent $\mathrm{SO}_{3}{ }^{+}$ion is present usually at very low levels, while the ${ }^{40} \mathrm{Ar}$ dimer ion precludes use of the most isotopically abundant ${ }^{80} \mathrm{Se}$ ion for HPLC monitoring. Two approaches to overcome this interference have been taken; a high-resolution mass spectrometer may be used, but thereby greatly increasing costs or a gas collision cell can be employed to destroy the argon dimer. We have observed a ten fold increace in signal upon monitoring the ${ }^{80} \mathrm{Se}$ in with the collision cell, by comparison with measuring ${ }^{82} \mathrm{Se}$ without the cell ${ }^{[29]}$. 


\begin{tabular}{|lll|}
\hline Se Isotope & \% Abundance & ICP-MS Ion Interferences \\
\hline 74 & 0.9 & $\mathrm{NiO}^{+}, \mathrm{ClCl}^{+}, \mathrm{ArAr}^{+}$ \\
76 & 9.0 & $\mathrm{NiO}^{+}, \mathrm{ArAr}^{+}$ \\
77 & 7.6 & $40 \mathrm{Ar}^{37} \mathrm{Cl}^{+}$ \\
78 & 23.5 & $40 \mathrm{Ar}^{38 \mathrm{Ar}^{+}} \mathrm{NiO}^{+}$ \\
80 & 49.8 & $40 \mathrm{Ar}^{40} \mathrm{Ar}^{+}$ \\
82 & 9.2 & $\mathrm{SO00}^{+}$ \\
\hline
\end{tabular}

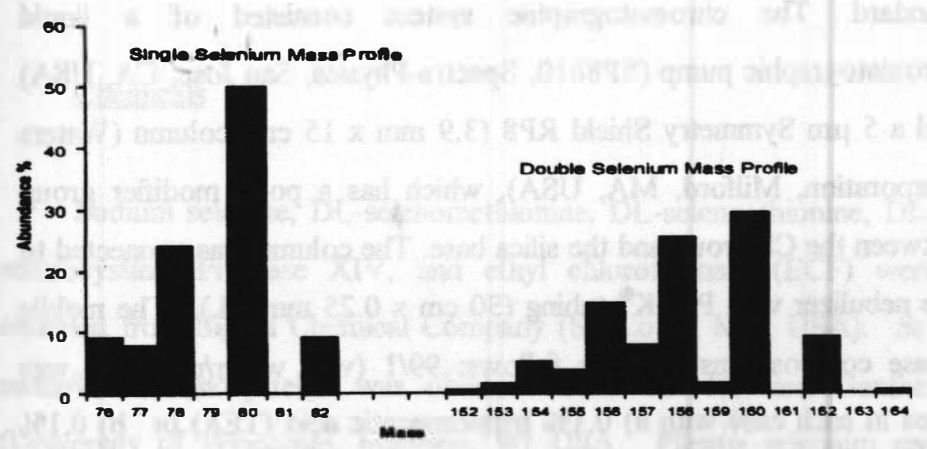

FIGURE 1. Isotopic Selenium Ion Profiles and Interferences

Aqueous and enzymatic extraction methods allow more than $90 \%$ of total selenium to be recovered and determined from matrixes such as selenized yeast. Trifluoroacetic acid and longer chain perfluoroalkanoic acid ion pair reverse phase HPLC gives good separation of selenite, selenate, methylseleninic acid, selenoaminoacids, selenoxides etc. The ICP-MS gives total element determination and selenium specific detection to 50-100 ppb and has been applied to a number of natural and enhanced level selenium speciation studies ${ }^{[30-34]}$. 


\section{EXPERIMENTAL}

\section{Instrumentation}

An Elan 5000 inductively coupled plasma mass spectrometer (Perkin-Elmer Sciex, Norwalk, CT, USA) was used for total selenium determination and HPLC-ICP-MS. Samples were introduced using a cross flow nebulizer and double pass spray chamber. For total selenium determination ${ }^{82} \mathrm{Se}$ and ${ }^{7} \mathrm{Se}$ were monitored with ${ }^{74} \mathrm{Ge}$ as an internal standard. The chromatographic system consisted of a liquid chromatographic pump (SP8810, Spectra-Physics, San Jose, CA, USA) and a $5 \mu \mathrm{m}$ Symmetry Shield RP8 $(3.9 \mathrm{~mm} \times 15 \mathrm{~cm})$ column (Waters Corporation, Milford, MA, USA), which has a polar modifier group between the $\mathrm{C} 8$ group and the silica base. The column was connected to the nebulizer with PEEK ${ }^{\bullet}$ tubing ( $30 \mathrm{~cm} \times 0.25 \mathrm{~mm}$ i.d.). The mobile phase compositions were as follows: $99 / 1$ (v/v) water/methanol was used in each case with a) $0.1 \%$ trifluoroacetic acid (TFA) or b) $0.1 \%$ heptafluorobutanoic acid (HFBA).

A Bruker-Agilent Esquire-LC mass spectrometer (Bruker-Franzen Analytik GmbH, Bremen, Germany) was used for the molecular mass spectral studies. For HPLC-ES-MS analysis the one $\mathrm{mL} / \mathrm{min}$ column eluent was split $1 / 5$ with a $T$ splitter. The $T$ splitter was connected to the ESI source with PEEK tubing $(8 \mathrm{~cm} \times 0.25 \mathrm{~mm}$ i.d.). Mass calibration and optimization of the operating parameters were performed daily and generally followed the manufacturer's guidelines. 
A Hewlett-Packard HP 5921A atomic emission detector (AED) interfaced with a HP 58901 gas chromatograph was used. The injection port (splitless) was maintained at $250^{\circ} \mathrm{C}$ : the $\mathrm{GC}$ oven was programmed from $100^{\circ} \mathrm{C}$ (initial temperature for $5 \mathrm{~min}$ ) to $200^{\circ} \mathrm{C}$ at $5^{\circ} \mathrm{C} / \mathrm{min}$, holding at $200^{\circ} \mathrm{C}$ for $5 \mathrm{~min}$. A HP-1 $25 \mathrm{~m} \times 0.32 \mathrm{~mm} \times 0.17 \mu \mathrm{m}$ (film thickness) column was used. The helium plasma gas flow was kept at $180 \mathrm{~mL} / \mathrm{min}$. The GC-AED used hydrogen as reagent gas, with detection at $181 \mathrm{~nm}$ (S) and $196 \mathrm{~nm}(\mathrm{Se})$.

\section{Chemicals}

Sodium selenate, DL-selenomethionine, DL-selenoethionine, DLselenocystine, Protease XIV, and ethyl chloroformate (ECF) were obtained from Sigma Chemical Company (St. Louis, MO, USA). Semethyl-DL-selenocysteine was obtained from Dr. Howard Ganther (University of Wisconsin, Madison, WI USA. Plasma selenium and germanium standard solutions $(1000 \mu \mathrm{g} / \mathrm{mL})$ were obtained from Spex Industries Inc., Edison, NJ, USA. Selenium-enriched yeast was obrained from Nutrition 21 (San Diego, CA, USA. Frizzedried selenium enriched garlic samples (1355 $\mu \mathrm{g} / \mathrm{g}$ and $296 \mu \mathrm{g} / \mathrm{g}$, selenium on a dry weight basis) were obrained from Dr. Clement Ip (Roswell Park Cancer Institute, Buffalo, NY). Stock solutions of selenoamino acids were prepared in $0.2 \mathrm{M} \mathrm{HCl}$. A stock solution of selenate was prepared in $2 \%(\mathrm{v} / \mathrm{v}) \mathrm{HNO}_{3}$, while the plasma selenium standard was used as a stock solution of selenite. Working solutions were diluted with mobile phase 
and stored in the dark between $0-4^{\circ} \mathrm{C}$. The standards used in measurements thus were $0.02-0.002 \mathrm{M}$ in $\mathrm{HCl}$ or $0.0002 \%$ in $\mathrm{HNO}_{3}$ after dilution, these acid concentrations having no effect on chromatographic separation and speciation considering the $10 \mu \mathrm{L}$ volumes injected.

\section{Speciation of Natural and Enriched Biological Materials}

In order to provide analytical characterization of selenium species for an ongoing study of the cancer chemopreventive activity of seleniun ${ }^{[34]}$, ion-paining reverse phase separation methods developed earlier ${ }^{[30,31]}$, using ICP-MS specific detection for selenium, were used to analyze various selenium-enriched biological samples, ramp (Allium tricoccum), onion (Allium cepa), garlic (Allium sativum), yeast and phytoremediation plants. Identification of selenium compounds was carried out chromatographically by a) retention time matching with peaks in the chromatogram of a standard mixture, comaining over 20 different selenium species and b) by spiking experiments with known standards. Two different perfluoro-aliphatic acids were used as ion paining agents, trifluoroacetic acid providing an overall profile with an acceptable combination of resolution and retention, while heptafluorobutyric acid afforded enhanced resolution in the early region of the chromatogram in which many low-level low molecular weight species typically elute. The percentage of the total selenium present in the various species in each sample was calculated from peak area measurements pertaining to the ${ }^{82} \mathrm{Se}$ ICP-MS signal. The integrated ion signal is independent of the molecular form of the analyte molecules. 
HPLC peaks present at sufficiently high concentrations (percent levels with respect to total $\mathrm{Se}$ ) were also characterized by electrospray - ion trap -MS for definitive identification.

A seleniumenriched yeast which has been the subject of extensive study (Nutrition 21 - 1922 ppm Se) demonstrates the major features of the analytical approach. Figure 2 shows a 20 minute segment of the lower resolution ion paired TFA chromatogram for the Protease XIV enzymatic extract, which shows the major profile features. Peak $A$ is selenomethionine and peak B is Se-adenosylseleno homocysteine. $\gamma$ Glutamyl- Se-methylselenocysteine is also present at a level below $1 \%$. By comparison, Figure 3 shows a 14-minute segment of the higher resolution ion paired HFBA chromatogram of the same extract. Selenomethionine is now retained for 13 minutes in contrast to three minutes, and the early eluting peaks show improved resolution. In relation to total eluted selenium compounds, peaks $b-f$ are tentatively identified by retention and spiking of standards and quantitated as bselenite ( $1 \%)$, c- selenolanthionine ( $1.5 \%), \mathrm{d}$ - selenocystine $(0.5 \%), \mathrm{e}$ selenocystathionine (1\%), f - Se-methylselenocysteine (0.5\%). These peaks could not yet be definitely confirmed by electrospray - ion trap MS at the (ng/peak) levels occurring. Peak $\gamma$-selenomethionine comprised $85 \%$ of eluted selenium and Se-adenosylseleno homocysteine, identified from the TFA chromatogram and by electrospray - ion trap MS, was present at $3 \%$ of the total. The peak eluting at 2.3 minutes which has peak ' $c$ ' as a shoulder remains unidentified and comprises 3$4 \%$ of the eluted selenium, possibly an important selenium species in a nutrition or cancer preventative context. 


\section{HPLC-ESI-MS analysis of selenium-enriched samples}

We reported the identification of the principal selenium compounds in 1922-ppm Se yeast and 296 ppm Se garlic using on-line HPLC-ESI-MS ${ }^{[35]}$. In those experiments TFA ion-paining agent was used, since the selenium compounds identified, (selenomethionine, $\gamma$ glutarmyl-Se-methylselenocysteine and Se-adenosyl-seleno-homo cysteine) eluted in the later parts of the chromatograms when interference from coeluting non-selenium compounds were minimal and the separation power of HFBA was not needed.

In the example shown (Figure 4), for the enzymatic extract of the 1355 ppm Se-garlic using HFBA, the upper trace depicts overlaid selected ion chromatograms (SIC) at $m / z$ values of 167,198 and 313 , and the background-corrected ion sum of the mass spectra under each SIC peak. The relative SIC peak areas are not indicative of relative amounts of each compound. The retention times and the mass spectra confirm the presence of Se-methylselenocysteine, selenomethionine and $\gamma$-glutamyl-Se-methylselenocysteine as the HPLC-ICP-MS measurements had indicated. In each instance the clear selenium isotope patterns for molecular ions reinforce the identifications.

The use of HFBA was necessary in this case because Semethylselenocysteine was only slightly retained when TFA was used.

Mass spectra could not be recorded despite its very high concentration. The additional non selenium-isotope ion patterns observed for each compound indicale some co-elution of non-seleniun 
species, which is not observed in the selenium-specific HPLC-ICP-MS chromatograms.

It is important to note that $\gamma$-ghutanyl -Se-methylselenocysteine predominates in the proteolytic extract of garlic enriched with selenium to a lower level (e.g. $296 \mathrm{ppm} \mathrm{Se}$ ) in contrast to Se-methylseleno cysteine which is predominant from the $1355 \mathrm{ppm}$ Se-garlic, and the selenomethionine from enriched yeast. ${ }^{[33,34]}$

Garlic samples containing $<300 \mathrm{ppm}$ Se all produce the $\gamma$-glutamyl derivative as a major storage form for selenium. Both $\gamma$-glutamyl -Semethylselenocysteine and Se-methylselenocysteine were identified in Astragalus bisulcatus ${ }^{[36]}$ and $\gamma$-glutamyl-S-alk(en)yl cysteines are known sulfur storage compounds in garlic $^{[37-39\}}$. Highly-enriched and moderately-enriched Se-garlic produced similar increases in tissue selenium provided that the total intake of selenium was the same. Considering the forms of selenium in the 1355 and 296-ppm Se garlic samples, it is reasonable to assume that $\gamma$-glutamyl-Se-methyl-seleno cysteine serves mainly as a carrier of Se-methylselenocysteine. 


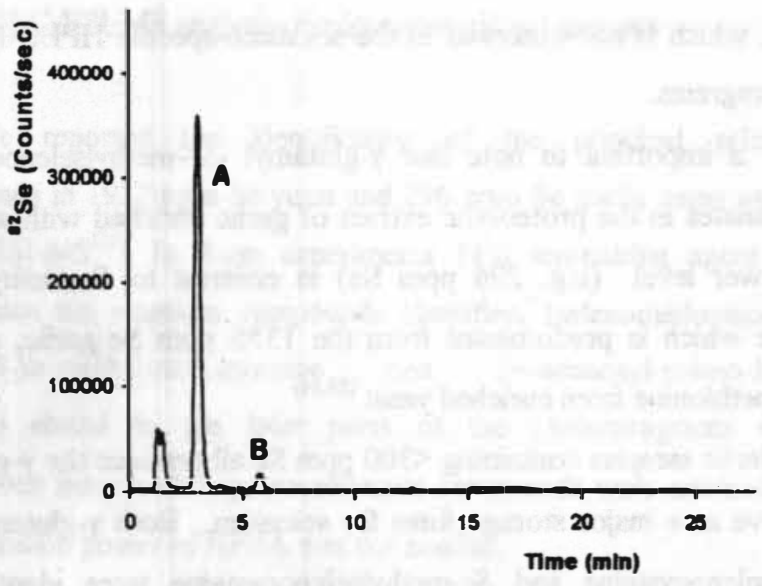

FIGURE 2. HPLC-ICP-MS chromatogram of Protease XIV extract of selenium-enriched yeast containing $1922 \mu \mathrm{g} / \mathrm{g}$ total Selenium. Trifluoracetic acid $(0.1 \%)$ ion pairing in mobile phase

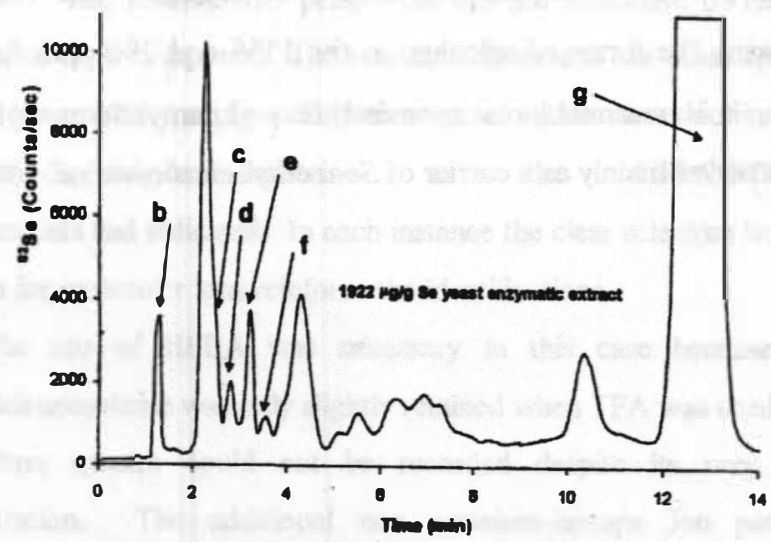

FIGURE 3. HPLC-ICP-MS chromatogram of Protease XIV extract of selenium-enriched yeast containing $1922 \mu \mathrm{g} / \mathrm{g}$ total Selenium. Heptafluorobutyric acid $(0.1 \%)$ ion pairing in mobile phase 

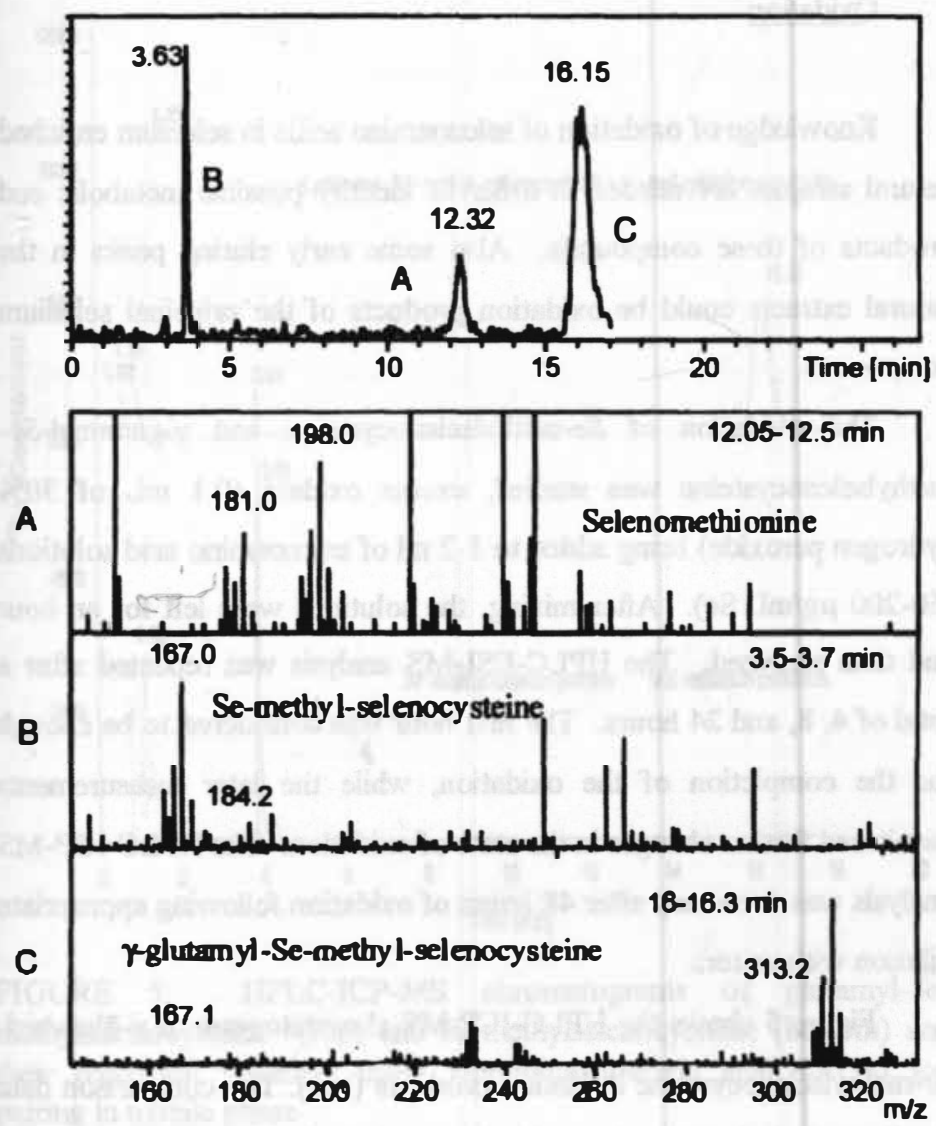

FIGURE 4. HPLC-Electrospray-MS single ion chromatographic peaks (SIC) overlaid (upper trace) and mass spectra (lower traces) of these peaks. Protease XIV extract of selenium-enriched garlic containing 1355 ppm total Selenium Heptafluorobutyric acid (0.1\%) ion pairing in mobile phase 


\section{Oxidation}

Knowledge of oxidation of selenoamino acids in selenium enriched natural samples are needed in order to identify possible metabolic end products of these compounds. Also some early eluting peaks in the natural extracts could be oxidation products of the principal selenium compounds.

The oxidation of Se-methylselenocysteine and $\gamma$-glutamyl-Semethylselenocysteine was studied, excess oxidant $(0.1 \mathrm{~mL}$ of $30 \%$ hydrogen peroxide) being added to $1-2 \mathrm{ml}$ of selenoamino acid solutions (50-200 $\mu \mathrm{g} / \mathrm{mL} \mathrm{Se).} \mathrm{After} \mathrm{mixing,} \mathrm{the} \mathrm{solutions} \mathrm{were} \mathrm{left} \mathrm{for} \mathrm{an} \mathrm{hour}$ and then analyzed. The HPLC-ESI-MS analysis was repeated after a total of 4, 8, and 24 hours. The first hour was considered to be enough for the completion of the oxidation, while the later measurements monitored further changes in the state of oxidation. The HPLC-ICP-MS analysis was done only after $\mathbf{4 8}$ hours of oxidation following appropriate dilution with water.

Figure 5 shows the HPLC-ICP-MS chromatogram of $\gamma$-glutamylSe-methylselenocysteine oxidation products (top). The comparison data for $\mathrm{Se}$-methylselenocysteine oxidation products is shown also (bottom). The segments of chromatograms depicted by darker lines correspond to the starting compounds, and those with lighter dotted lines relate to their oxidation products. The retention data of the oxidation products of glutamyl-Se-methylselenocysteine indicates the presence of selenite, selenate and methaneseleninic acid, the latter being the principal oxidation product. 


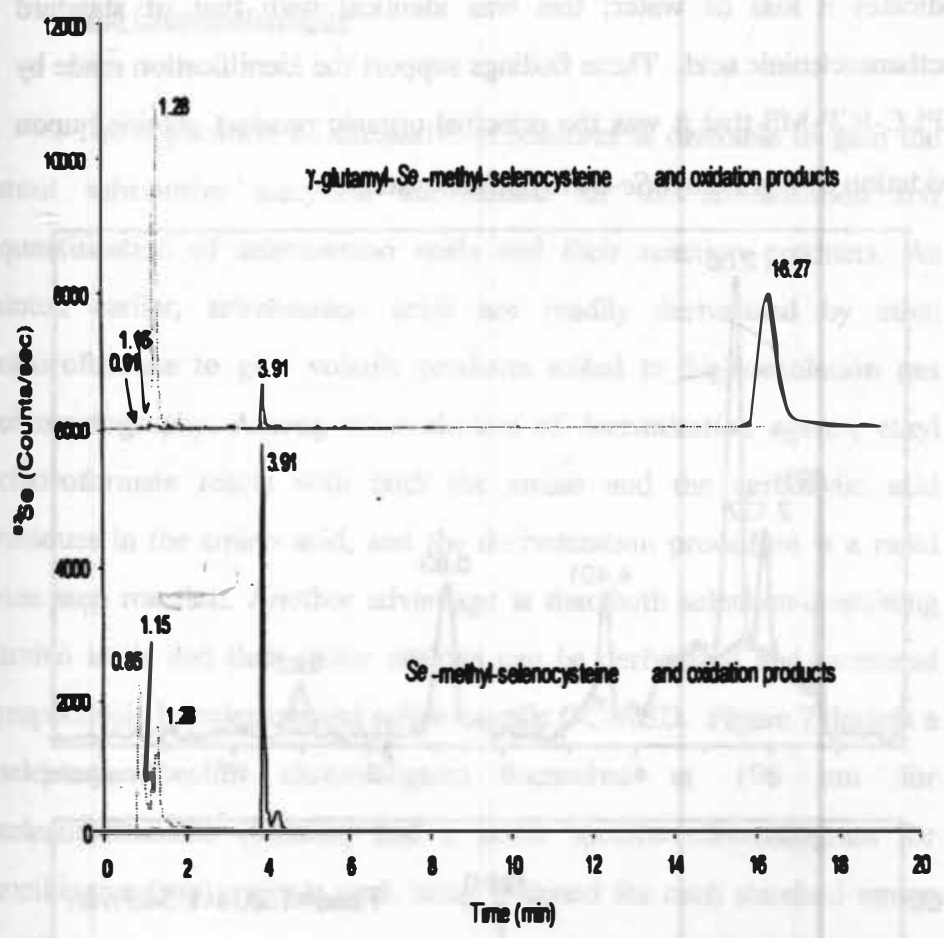

FIGURE 5. HPLC-ICP-MS chromatograms of glutamyl-Semethylselenocysteine (top) and Se-methylselenocysteine (bottom) and their oxidation products using Heptafluorobutyric acid $(0.1 \%)$ ion paining in mobile phase

The HPLC-ESI-MS total ion chromatogram of the oxidation products is shown in Figure 6 indicating six distinct peaks. Only the peak eluting at $1.291 \mathrm{~min}$. showed the selenium isotope pattern, as predicted by the HPLC-ICP-MS chromatogram (Figure 5). The mass spectrum in Figure 6 is the ionic sum of the spectra under the peak at $1.291 \mathrm{~min}$. The $\mathrm{m} / \mathrm{z}=129$ indicates the $\mathrm{M}+1$ ion, and $\mathrm{m} / \mathrm{z}=111$ 
indicates a loss of water; this was identical with that of standard methaneseleninic acid. These findings support the identification made by HPLC-ICP-MS that it was the principal organic product obtained upon oxidation of $\gamma$-glutamyl-Se-methylselenocysteine.
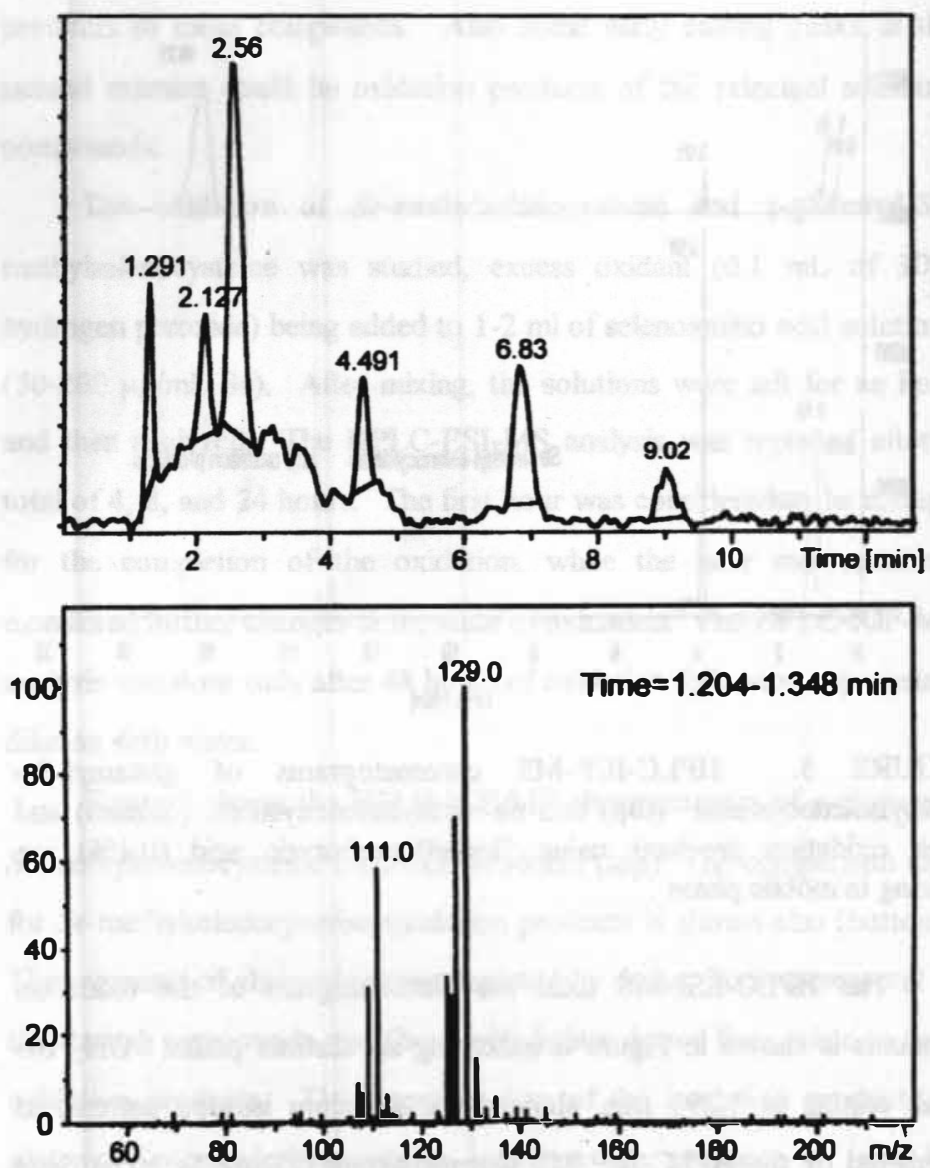

FIGURE 6. HPLC-Electrospray-MS total ion chromatographic peaks (TIC) (upper trace) and mass spectrum (lower trace) of the oxidation product(s) of $\gamma$-glutanyl-Se-methylselenocysteine. 


\section{Gas Chromatography}

The application of alternative procedures is desirable to gain the most substantive analytical information for the identification and quantification of selenoamino acids and their reaction products. As noted earlier, selenoamino acids are readily derivatized by ethyl chloroformate to give volatile products suited to high-resolution gas chromatography. Among other choices of derivatization agents, ethyl chloroformate reacts with both the amino and the carboxylic acid residues in the amino acid, and the derivatization procedure is a rapid one step reaction. Another advantage is that both selenium-containing amino acids and their sulfur analogs can be derivatized and measured respectively by selenium and sulfur specific GC-AED. Figure 7 depicts a selenium specific chromatogram measured at $196 \mathrm{~nm}$ for selenomethionine (bottom) and a sulfur specific chromatogram for methionine (top) a single peak being obtained for each standard amino acid.

Work is in progress to quantify the percentage efficiency of the derivatization and to implement this derivatization for the proteolytic degradate of high selenium yeast and other materials. The aim is to independently characterize the selenium containing compounds identified using the HPLC method, and to obtain relative proportions of analogous sulfur and selenium amino acids. 

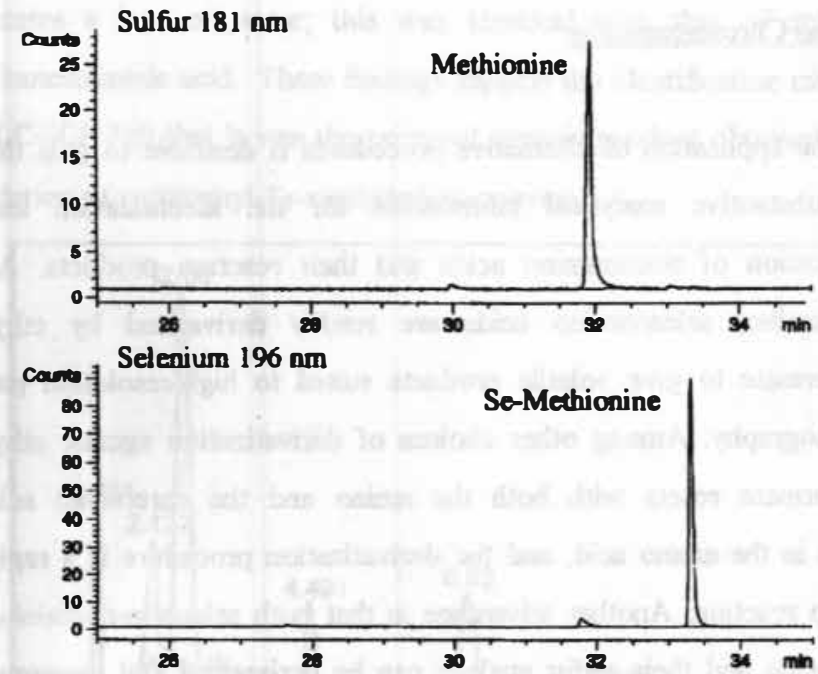

FIGURE 7. GC-AED chromatograms of ethylated derivatives of methionine (top - $181 \mathrm{~nm}$ ) and selenomethionine (bottom - $196 \mathrm{~nm}$ ).

\section{CONCLUSIONS}

Advances in analytical methodology are having and will surely have an increasingly major impact on qualitative, quantitative and reactivity aspects of selenium chemistry, notably as it applies in the fields of nutrition, biochemistry and clinical efficacy. The great advantages imparted by element specific detection for selenium enable conclusive data to be obtained for systems, which were previously intractable. 


\section{ACKNOWLEDGEMENTS}

This work was supported in part by the NIH (CA45164) and the NRI Competitive Grants Program/USDA (Award No. 96-355003351). The Perkin-Elmer Corporation is acknowledged for provision of the Elan 5000 plasma source mass spectrometer and for data obtained on the Elan 6100 instrument. The provision of the Symmetry Shield RP8 columns by Waters Chromatography Corp. is gratefully acknowledged. Eric Denoyer and Ray Crowley are thanked for their interest and assistance. The authors also thank John Gray (ETP) for providing the detector upgrade for the ICP-MS.

Any opinions, findings, and conclusions or recommendations expressed in this material are those of the authors and do not necessarily reflect the views of the specific granting agency.

\section{References}

[1] O. Wada, N. Kurihara, N. Yamazaki, Jap. J. Nutr. Assess. 10, 199 (1993).

[2] H.E. Ganther, Carcinogenesis, 20(9), 1657 (1999).

[3] O.A. Levander, Annu. Rev. Nutr. 7, 227 (1987).

14] H.E. Ganther and J.R. Lawrence, Tetrahedron, 53, 12229 (1997).

[5] X. Dauchy, M. Potin Gautier, A. Astruc, M. Astruc, Fresenius' J Anal Chem., 348, 792 (1994).

[6] K. Pyrzynska, Chem Anal. 40, 677 (1995).

[7] K. Pyrzynska, Analyst, 121, 77R (1996).

[8] G. Kölbl, K. Kalcher, K.J. Irgolic, R.J. Magee, Appl. Organomet. Chem. 7, 443 (1992).

[9] D. Behne, C. Hammel, H. Pfeifer, D. Rothlein, H. Gessner, A. Kyriakopoulos, Analyst 123, 871 (1998).

[10] L.C. Clark, G.F. Combs, B.W. Turnbull, E.H Slate, D.K Chalker, J Chow, L. S Davis. R.A Glover, G.F Graham, E.G Gross, A. Krongrad, J.L. Lesher, K. Park, B.B. Sanders, C.L. Smith and R. Taylor, J. Am. Med. Assoc.; 276, 1957 (1996).

[11] C. Ip, D.J. Lisk and G.S. Stoewsand, Nutr. Cancer, 17, 279 (1992).

[12] C. Ip and D.J. Lisk, Carcinogenesis, 16, 2649 (1995).

[13] C. Ip, Z. Chu, H.J. Thompson, D.J. Lisk and H.E. Ganther, Anticancer Res., 19, 2875 (1999).

[14] R. Lobinski, J. Edmonds, K.T. Suzuki And P.C. Uden, Pure Appl. Chem., 72(3) 447 (2000).

[15] R. Sathe, A.C. Mason, R. Rodibaygh, W.C.M., J. Agric. Food Chem., 40, 2084 (1992).

[16] Element Specific Chromatographic Detection by Atomic Emission Spectroscopy, P.C. Uden (editor), Washington, D.C. (1992), ACS Symposium. Series., 479 (1992).

[17] R. Lobinski, Appl Spectrosc., 51, 260)A (1997).

[18] B.D. Quimby, P.C. Uden and R.M. Bames Anal. Chem., 50, 2112 (1978). 
[19] P.C. Uden, Element-Specific Chromatographic Detection by Atomic Emission Spectroscopy, American Chemical Society Symposium Series \#479, ACS, Washington DC (1992).

[2()] X. -J. Cai, P.C. Uden, E. Block X. Zhang, J.J. Sullivan, and B.D. Quimby. J. Ag. Food Chem, 42, 2085 (1994).

[21] X. -J. Cai, E. Block, P.C. Uden, J.J. Sullivan, and B.D. Quimby, J. Ag. Food Chem., 43, 1751 (1995).

[22] J.A. Seeley, Y. Zeng, T.I. Eglinton, I. Ericsson, and P.C. Uden, J. Anal At. Spectrom., 7, 979 (1992).

[23] H. Kataoka, Y. Miyanaga, M. Makita, J Chromatogr A, 659, 481 (1994).

[24] X. -J. Cai, E. Block P.C. Uden, X. Zhang, J.J. Sullivan, and B.D. Quimby J. Ag. Food Chem., 43, 1754 (1995).

[25] K. Yasumoto, T. Suzuki, M. Yoshida, J Agric Food Chem., 36, 463 (1988).

[26] Z. Ouyang, J. Wu, L. Xie, Anal Biochem, 178, 77 (1989).

[27] O. Zheng, J. Wu, Biomed Chromatogr. 2, 258 (1988).

[28] T.G. Chasteen Appl. Organomet. Chem., 7, 335 (1993).

[29] R. Hafezi, P.C. Uden and J.F. Tyson, unpublished observations.

[3()] P.C. Uden, S.M. Bird, M. Kotrebai, P. Nolibos, J.F. Tyson, E, Block and E.R. Denoyer, Fresenius J. Anal Chem., 362447 (1998).

[31] M. Kotrebai, S.M. Bird, J.F. Tyson, E. Block and P.C. Uden, Spectrochimica Acta B,., 541573 (1999).

[32] M. Kotrebai, J.F. Tyson, E. Block and P.C. Uden, J, Chromatog. 86651 (2000).

[33] M. Kotrebai, M. Birringer, J.F. Tyson, E. Block and P.C. Uden. Analyst 12571 (2000).

[34] C. Ip, M. Birringer, M.E, Block, Kotrebai, J.F. Tyson, P.C. Uden and D.J. Lisk, J. Ag. Food Chem., 482062 (2000).

[35] M. Kotrebai, M. Birringer, J.F. Tyson, E. Block and P.C. Uden. Anal. Commun., 36249 (1999).

[36] S. N Nigan and W.B. McConnell, Biochim. Biophys. Acta 192185 (1969).

[37] A.I. Virtanen, Phytochemistry 4:207 (1965).

[38] H.P. Koch, and L.D. Lawson, Garlic. The science and therapeutic applications of Allium sativum L. and related species,Baltimore (MD): William \& Wilkens (1996).

[39] Block, E. Angew: Chem. Int. Ed. Engl. 31:1135 (1992). 